\title{
Colorectal Adenoma
}

National Cancer Institute

\section{Source}

National Cancer Institute. Colorectal Adenoma. NCI Thesaurus. Code C5673.

An adenoma that arises from the colon or rectum. The group of colorectal adenomas

includes tubular, villous, and tubulovillous adenomas, traditional serrated adenomas, sessile serrated adenomas/polyps, and familial adenomatous polyposis. 